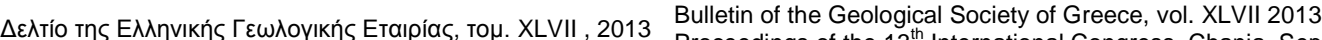

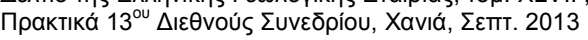

\title{
ROCKFALLS: INFLUENCE OF ROCK HARDNESS ON THE TRAJECTORY OF FALLING ROCK BLOCKS
}

\author{
Asteriou P. ${ }^{1}$, Saroglou H. ${ }^{1}$ and Tsiambaos G. ${ }^{1}$ \\ ${ }^{l}$ National Technical University of Athens, School of Civil Engineering, Geotechnical Department, \\ paster@central.ntua.gr,saroglou@central.ntua.gr,gktsiamb@central.ntua.gr
}

\begin{abstract}
Rockfalls pose significant hazard on human activities and infrastructure. The assessment of rockfall risk along roads and on other human activities is of great importance. Geological assessment can predict the outbreak of such events; explain the mechanism of occurrence and assist in the effective design of protection measures. The trajectory of a falling block is significantly affected by its response to the impact with the slope, since block kinematics properties mainly depend on the coefficient of restitution values. In this research a laboratory procedure based on the free fall of small blocks of different rock types and artificial materials was implemented in order to address the effect of their mechanical properties on the coefficient of restitution values. From the evaluation of testing results a correlation between kinematic coefficient of restitution and Schmidt rock hardness is proposed. Key words: Rockfalls, Coefficient of restitution, Laboratory testing.
\end{abstract}

\section{Пєрí $\eta \psi \eta$}

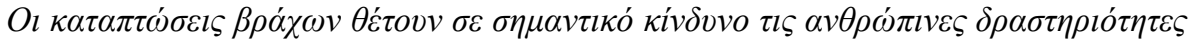

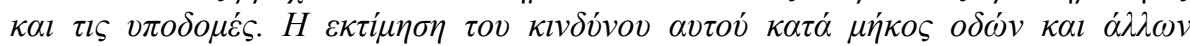

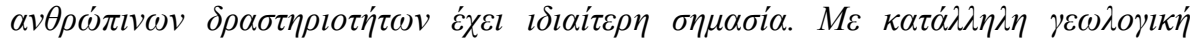

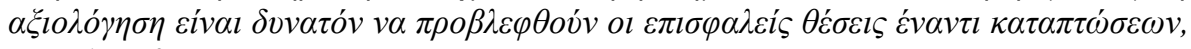

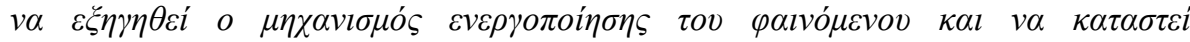

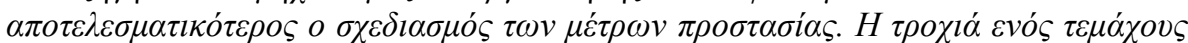

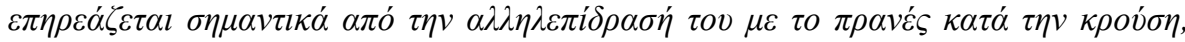

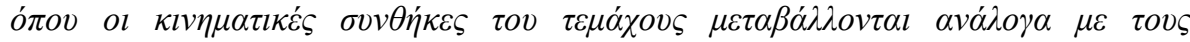

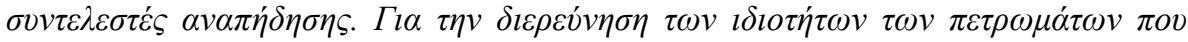

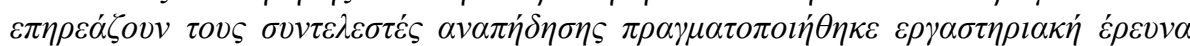

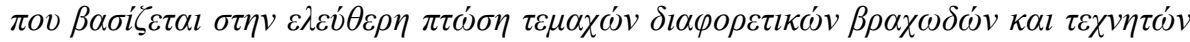

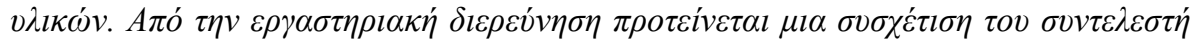

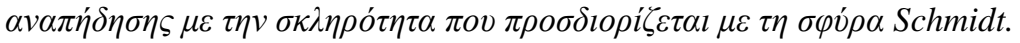

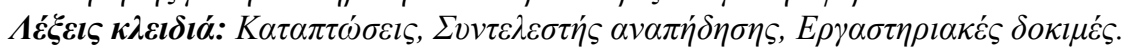

\section{Introduction}

Rockfalls pose a significant hazard on human activities and infrastructure. The geological structure of Greece favors such events; the mountainous terrain - steep topography in combination with the frequent occurrences of rock formations and the overall high seismicity create a significant

XLVII, No $3-1684$ 
rockfall risk, as shown from recent events. Slope movements, which occur in the form of rockfalls, are the most frequent type in Greece, with a frequency of about 55\% (Koukis et al., 1994).

A number of rockfalls have occurred in Greece in the recent years, i.e. Achaia, Lefkada, Skyros and others. The major rockfall event at Tempi in 2009 resulted in human loss and temporary closure of the Athens - Thessaloniki National road. Additionally, recent events with casualties occurred in Argos and Santorini, which all outline the significance of rockfall assessment and mitigation.

Two distinct stages constitute the rockfall phenomenon; the initial stage and the post-failure stage. The first describes the circumstances under which a block is detached from a slope. Rockfall intensity increases radically during periods of low temperature and high rainfall (Attewell et al., 1976). The post-failure stage describes the motion of the block along the rock slope. The study of the resulting block trajectory raises many uncertainties due to the number of parameters involved.

The outbreak of rockfalls can be predicted by geological hazard assessment. However, in order to quantify the risk, the exposure to the hazard must be determined. In a rockfall event the exposure is estimated based on the trajectory of the block. Additionally, the kinematic characteristics of the trajectory are the main parameters used for the design of remedial measures. Thus, the importance of a reliable trajectory analysis is crucial in order to address rockfall phenomena.

This paper presents part of the experimental research concerning rockfall trajectory modeling, currently held in the Engineering Geology - Rock Mechanics Laboratory of the School of Civil Engineering at the National Technical University of Athens. The response of a rock block impacting a rock slope is considered as the most important aspect. In relevant literature, this is connected to a qualitative characterization of the rock material, whereas in this research study a quantified approach is attempted.

\section{Literature Review}

\subsection{Rockfall Trajectory Modeling}

The trajectory of a block can be modelled as a combination of four movement types: free flight (or preferably aerial phase), rolling, sliding and bouncing (Descoeudres et al., 1987). The aerial phase is relatively easy to study; the general equations of motion for the block projectile describe adequately this part of the motion. Rolling and sliding are mainly controlled by the interaction of the block with the slope and they are affected from many parameters, among which are the friction angle, slope roughness, block shape. Bouncing is the most difficult part of the motion to predict, due to its complexity and its very limited understanding (Labiouse et al., 2009). The parameters, which influence the bouncing phenomenon, are summarized in Table 1.

Table 1 - Parameters assumed to influence the bouncing phenomena (Labiouse et al., 2009).

\begin{tabular}{|c|c|c|}
\hline $\begin{array}{c}\text { Slope } \\
\text { characteristics }\end{array}$ & $\begin{array}{c}\text { Block } \\
\text { characteristics }\end{array}$ & Kinematics \\
\hline Strength & Strength & Translational velocity \\
\hline Stiffness & Stiffness & Rotational velocity \\
\hline Roughness & Weight - Size & Collision angle \\
\hline Inclination & Shape & $\begin{array}{c}\text { Configuration of block } \\
\text { at impact }\end{array}$ \\
\hline
\end{tabular}

Trajectory analysis is performed via computer simulation software, most commonly based on lumped mass model approach, in which the block is considered to be a point with a concentrated 
mass. The most important input parameters, regarding block's trajectory, are the so-called coefficients of restitution, which describe the response of the block to an impact.

\subsection{Coefficients of Restitution}

In general, the coefficient of restitution (COR) is defined as the value representing the ratio of velocities (or impulses or energies; depending on the definition used) before and after an impact of two colliding entities. Theoretically, a COR that equals one corresponds to a perfect elastic collision, a COR value less than 1 defines an inelastic collision and a COR that equals zero is obtained when the object instantaneously stops at the surface area without bouncing, hence a perfectly plastic behavior (Goldsmith, 1960).

Various definitions on the coefficients of restitution have been proposed, such as the kinematic, kinetic or energy coefficients of restitution, but it seems that there is no consensus on which of them is more appropriate for rockfall trajectory prediction (Chau et al., 2002). The kinematic approach, which is derived from the inelastic collision of particles in the Newtonian mechanics, is the most commonly used due to its overall simplicity.

When the block comes in contact with the slope, its velocity changes according to the COR value. Hence, COR is assumed to be an overall value that takes into account all the characteristics of the impact; including deformation, sliding upon contact point, transformation of rotational moments into translational and vice versa, etc (Giani, 1992).

For an object impacting a steadfast surface the COR definition, known as kinematic coefficient of restitution $\left(\mathrm{v}_{\mathrm{COR}}\right)$, is simplified as:

Equation 1 - Kinematic Coefficient of Restitution, $v_{\text {COR }}$

$v_{C O R}=\frac{v_{r}}{v_{i}}$

where $v_{r}$ and $v_{i}$ are the magnitudes of the rebound and impact velocities of block, respectively. For an initial free-fall motion of the block, which impacts on a horizontal surface, equation 1 yields to:

\section{Equation 2 - Kinematic Coefficient of Restitution, $v_{C O R}$}

$v_{C O R}=\sqrt{\frac{h_{r}}{h_{d}}}$

where $h_{r}$ is the maximum height gained after impact and $h_{d}$ the block release height.

The most common definition is derived from the normal and tangential to the impact surface projections of the velocity vector. Hence, the normal $\left(\mathrm{n}_{\mathrm{COR}}\right.$ or $\left.\mathrm{Rn}\right)$ and the tangential $\left(\mathrm{t}_{\mathrm{COR}}\right.$ or $\left.\mathrm{Rt}\right)$ coefficients of restitution are defined as:

Equation 3 - Normal Coefficient of Restitution, $\mathbf{n}_{\mathrm{COR}}$

$n_{C O R}=\frac{v_{n r}}{v_{n i}}$

Equation 4 - Tangential Coefficient of Restitution, $t_{\text {COR }}$

$t_{C O R}=\frac{v_{t r}}{v_{t i}}$ 
where the first subscript, $\mathrm{n}$ or $\mathrm{t}$ denotes the normal or the tangential components of the velocity, and the second subscript $i$ and $r$ denote the impacting or the rebounding velocities respectively.

Typical values of these coefficients can be found in the literature, e.g. (Heidenreich, 2004) and (Richards et al., 2001), but these values depend on the slope and block material type and in some cases on the vegetation cover. This is considered an oversimplification, which can lead to miscalculations, since the response of a colliding block is controlled by many other parameters, as previously mentioned. A more accurate method for the estimation of the coefficient values is by performing back analysis on known rockfall trajectories and comparing with those determined in the laboratory (Saroglou et al., 2010).

\subsection{Relevant Experimental Studies}

Coefficients of restitution can be determined either by experimental studies or by back-analysis with computer simulations of the field evidences induced from natural rockfall events, such as the impact marks and run-out distances (Paronuzzi, 2009). Experimental studies are made either with the aid of physical models or with in situ testing (i.e. Spadari et al., 2012). In literature, little evidence from experimental research with physical models exists. Due to the randomness caused by the shape of the falling rock block, most researchers have used artificial materials, which could be easily formatted into spheres (Chau et al., 2002). Experimental research studies with natural rock materials and angular boulders are therefore limited.

A relevant study (Richards et al., 2001) was conducted with free fall drop tests on different rock types (basalt, diorite, gneiss, granite, limestone, marble, rhyolite, sandstone and schist), and also on debris and soil materials. The following correlation between the normal COR and the Schmidt hammer rebound hardness values $(\mathrm{R})$ of both the block and the impacting surface, as well as the impact surface's angle $(\theta)$ was proposed.

Equation 5 - Correlation of Normal Coefficient of Restitution $\left(\mathbf{n}_{\mathrm{COR}}\right)$ with Schmidt Hammer Rebound Hardness and slope inclination

$$
n_{\text {COR }}=\frac{-110+9 R_{\text {slab }}+4 R_{\text {ball }}+4 \theta}{1000}
$$

where $R_{\text {slab }}$ and $R_{\text {ball }}$ are the Schmidt hammer rebound hardness values for the impact surface and the block respectively, and $\theta$ the angle of impact surface in degrees. The aforementioned correlation indicates that the hardness of the falling block affects less the normal COR value than the hardness of the impact surface. Furthermore, from Equation 5 it is observed that normal COR increases with the impact surface's angle

Asteriou et al. (2012), carried out an experimental physical model research study with cubical boulders from various rock types of the Greek territory (i.e. marble, schist, limestone, sandstone and marl), seeking the effect of Schmidt hardness coefficient on COR values. The following correlation was proposed:

\section{Equation 6 - Correlation of Kinematic Coefficient of Restitution $\left(v_{C O R}\right)$ with Schmidt} Hammer Rebound Hardness

$$
v_{C O R}=0.235 \exp (0.022 R)
$$

The experimental study presented hereafter is an extension of the previously mentioned study, concerning three more rock types and three artificial materials. Additionally, all materials were tested according to ISRM (2007), in order to examine the effect of the mechanical properties on COR values. 


\section{Laboratory Investigation}

\subsection{Experimental Setup}

Almost cubic shaped rock specimens with smooth edges were used as colliding blocks (Figure 1a). The surface area, upon which the impact of the blocks occurred, was a smooth and planar plate with $5 \mathrm{~cm}$ thickness formed by the same material as the impacting block. The plate was embedded in plaster in order to obtain a square shape with $15 \mathrm{~cm}$ sides (Figure 1b), able to adjust in a massive dead weight base, ensuring the preservation of the momentum caused by the impact.

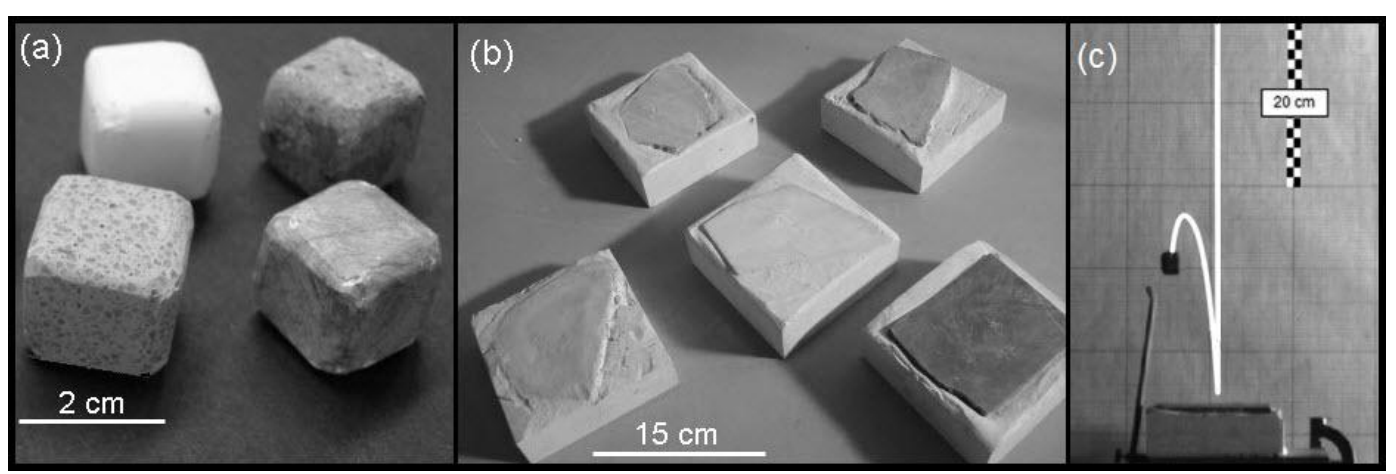

Figure 1 - Colliding blocks (a); impact surfaces (b); and recorded trajectory (c).

The release mechanism used for the tests constituted of an arm where the block was attached and held with suction produced by a vacuum pump. By switching the vacuum pump off, suction force reduces letting the block to a free fall drop from a height of $80 \mathrm{~cm}$, developing only vertical translational velocity prior to impact.

The trajectory of the blocks (Figure 1c) was recorded with a digital high-speed video camera, at a capture speed of $250 \mathrm{fps}$ and resolution of $640 \mathrm{x} 480$ pixels. The camera was fixed with its axis perpendicular to the trajectory plane $\mathrm{XY}$, in order for the capture plan to be parallel to the trajectory plane leading to a two dimensional projection. The recorded video was then analyzed with an image analysis software, providing the coordinates $\mathrm{x}, \mathrm{y}$ and the time of each frame. These data were processed by an Excel routine in order to determine the coefficients of restitution.

\subsection{Materials}

The rock types of blocks and impact surfaces tested were: marble, schist, green schist, crystalline limestone, limestone, quartz sandstone and marl. Two types of marble were tested; type I exhibiting a micro-sparitic, calcitic and granular texture and type II of a similar composition but with a micritic texture, both with an origin from the ancient quarries of Penteli Mountain. Schist is a calcitic mica-schist with well-developed schistosity, sampled from Hymettus Mountain. The green Schist has a pronounced schistosity and originates from Tempi area in central Greece. Crystalline limestone has a fine texture, sampled from Lavrion area, Attica. Limestone is a sparitic limestone, obtained from Tourkovounia hill in Athens. Sandstone is quartzitic, medium to coarse grained, grey-colored from Kalydona tunnel in western Greece. Marl is a limey one, obtained from Derveni area in the Northern Peloponnesian coast.

Three artificial materials were also tested: an epoxy resin grout, a high strength cement-based grout and a mixture of polyester with quartzitic sand. The use of artificial materials has two main advantages: first that different shapes can be easily achieved which allows the investigation of shape effect and second that their mechanical properties can be chosen in order to fulfill the requirement of similarity between laboratory and field tests. The purpose of using these artificial materials in the current study was to compare the properties between natural and artificial 
materials, in order to be used in the aforementioned tasks which are part of the ongoing research currently held by the authors.

The physical and mechanical properties of the tested materials, which are summarized in Table 2, were determined according to ISRM suggested methods (ISRM, 2007). The following tests were performed: a) Ultrasonic test, B) Schmidt rebound hardness test (L-type), c) Uniaxial compression strength test with measurement of elastic properties, d) Indirect tensile strength test (Brazilian test). Diametrical and axial displacements, during the UCS tests, were measured by circumferential and dual axial extensometers.

Table 2 - Physical and Mechanical Properties of Tested Materials.

\begin{tabular}{|l|c|c|c|c|c|c|c|c|}
\hline \multicolumn{1}{|c|}{ Material Type } & $\begin{array}{c}\boldsymbol{\rho} \\
\mathbf{k N} / \mathbf{m}^{\mathbf{3}}\end{array}$ & $\begin{array}{c}\boldsymbol{\sigma}_{\mathbf{c}(\mathbf{5 0})} \\
\mathbf{M P a}\end{array}$ & $\begin{array}{c}\mathbf{E}_{\mathbf{t}} \\
\mathbf{G P a}\end{array}$ & $\mathbf{v}$ & $\begin{array}{c}\boldsymbol{\sigma}_{\mathbf{t}} \\
\mathbf{M P a}\end{array}$ & $\begin{array}{c}\mathbf{V p} \\
\mathbf{m} / \mathbf{s}\end{array}$ & $\begin{array}{c}\mathbf{V s} \\
\mathbf{m} / \mathbf{s}\end{array}$ & $\mathbf{S H V}$ \\
\hline Marble I & 25.2 & 66.1 & 40.2 & 0.261 & 6.2 & 4954 & 2861 & 38.2 \\
\hline Marble II & 27.6 & 143.0 & 83.7 & 0.217 & 13.7 & 4130 & 2822 & 50.8 \\
\hline Schist & 23.6 & 17.5 & 2.4 & 0.157 & 4.7 & 2208 & 1348 & 22.3 \\
\hline Green Schist & 26.1 & 23.1 & 15.1 & 0.109 & 4.6 & 4439 & 2914 & 30.7 \\
\hline Crystalline limestone & 25.6 & 52.9 & 40.8 & 0.124 & 6.6 & 6013 & 3322 & 36.7 \\
\hline Limestone & 26.2 & 67.0 & 44.2 & 0.221 & 5.0 & 5828 & 3240 & 36.1 \\
\hline Sandstone & 25.2 & 107.5 & 35.4 & 0.252 & 11.3 & 4606 & 2981 & 44.7 \\
\hline Marl & 22.1 & 2.6 & 1.8 & 0.123 & 0.5 & 1733 & 1188 & 18.2 \\
\hline Epoxy Resin & 20.4 & 86.5 & 11.0 & 0.377 & 15.6 & 4125 & 2429 & 42.3 \\
\hline Cement Grout & 21.9 & 37.4 & 15.7 & 0.113 & 7.5 & 4335 & 2574 & 33.4 \\
\hline Polyester & 16.9 & 90.2 & 5.2 & 0.451 & 20.5 & 3295 & 1675 & 41.8 \\
\hline
\end{tabular}

\subsection{Experimental Assumptions}

According to the lumped-mass model, the angular velocity of falling rock block is not taken into account for the determination of COR values (Equations 1-4). Therefore, angular velocity was not measured in the performed tests. Additionally, the geometry of the falling block and its orientation during impact were not considered, even though both affect the trajectory. These parameters result in deviations from real rockfall conditions and they are not considered in the lumped-mass model, therefore COR values for blocks with random shapes are unreliable. However, modeling with the lumped-mass theory using those values is a common in rockfall engineering practice.

Theoretically, the rebound angle of a spherical object impacting on horizontal surface should be $90^{\circ}$. However, due to the cubical shape of the blocks and their orientation at impact, the values of rebound angles have a wide range. When rebound deviates from the vertical direction, normal COR is underestimated since the energy dissipating in the horizontal direction becomes more significant. Hence, a number of tests were executed for each material but only the $25 \%$ of the impact tests with the least deviation from vertical direction were furthermore analyzed. Additionally, tangential COR, which could describe the horizontal energy dissipation, cannot be defined for a free fall motion (Equation 4), because the tangential velocity before impact is zero. However, normal and tangential COR of cubic blocks can be estimated from kinematic COR according to the proposed methodology by Asteriou et al. (2012). 


\section{Evaluation of Results}

\subsection{Comparison of Normal COR with Kinematic COR}

The normal and kinematic COR were determined based on equations 1 and 3 using the data results from the performed tests. The relation between the ratio of normal to kinematic COR and the rebound angle is presented in Figure 2. As previously mentioned, when the block's rebound trajectory deviates from vertical direction, therefore when the rebound angle receives low values, the normal COR is underestimated. The data points $(n=110)$ plotted represent the $25 \%$ of the tests for each material which show the least deviation.

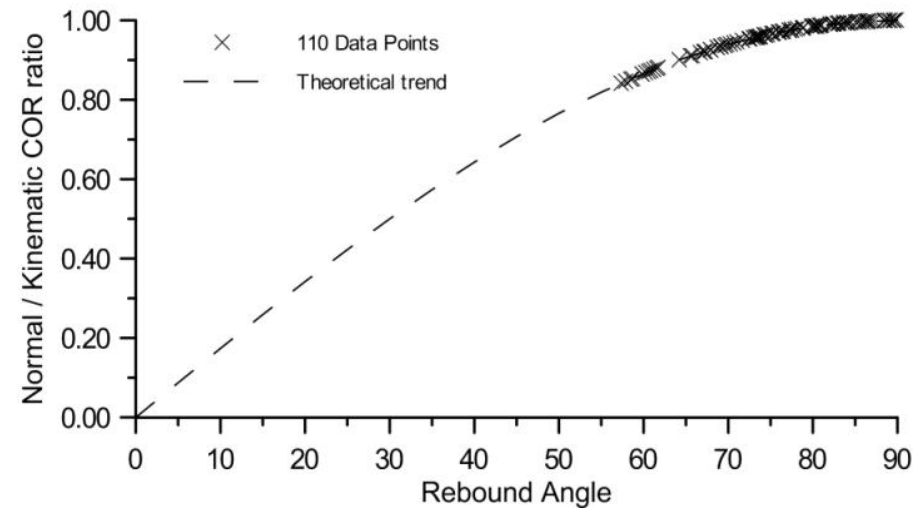

Figure 2 - Effect of rebound angle on the Normal/Kinematic COR ratio.

\subsection{Applicability of COR Value Correlations with Physical-Mechanical Properties}

Normal and kinematic COR values versus the Schmidt Hammer (SH) rebound hardness values are presented in Figure 3. It is observed that both coefficients values increase as the material hardness increases; which has been stated as a general rule in rockfall studies. From the present research data it is observed that the kinematic COR is more consistent compared to normal COR and thus its use is preferable when correlating with material properties. In Figure $3 b$, the probability boundaries at $75 \%$ and $100 \%$ are shown. The mathematical expressions defining these boundaries and their regression coefficients are also shown, denoting strong correlations.
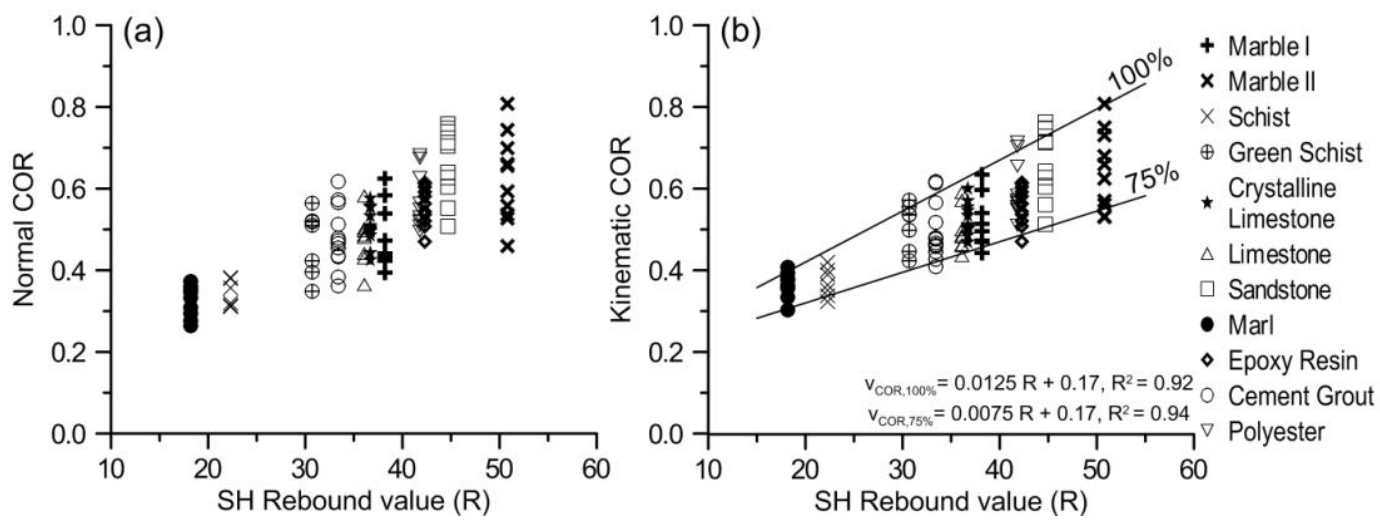

Figure 3 - Normal (a) and Kinematic (b) COR against Schmidt Hammer rebound hardness.

Kinematic COR values increase with increasing compressive and tensile strength as shown in Figure 4. Additionally, the probability boundaries for kinematic COR are also presented. However, in Figure 4b, these boundaries have been calculated without considering the tests held with polyester and epoxy resin samples (encircled values). These are not taken into account due to their 
bulging behaviour, which results in high tensile strength, greater than the expected for rock materials.
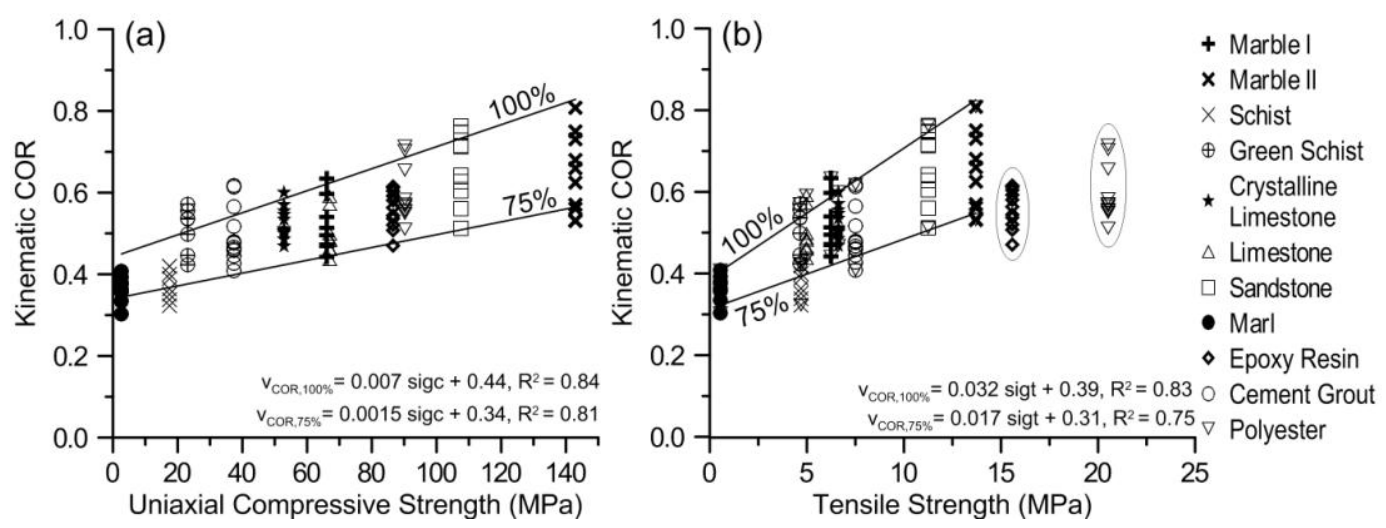

Figure 4 - Kinematic COR against compressive (a) and tensile (b) strength.

Tangent Young's modulus and Poisson's ratio were determined during uniaxial compression tests for all materials. Kinematic COR values against tangent Young's modulus are presented in Figure 5a. Although rebound is affected by the elastic properties of the colliding entities, which control the extent of plastic deformation during impact, a trend between Young's modulus and kinematic $\mathrm{COR}$ is not clearly expressed from the analysis of the testing data. Similarly, no trend was found with the Poisson's ratio.

Compression and shear wave velocities were also determined for all tested materials. As shown in Figure 5b quantitative correlation between Kinematic COR values and P-wave velocity is not applicable. This is also valid for the relation between kinematic COR and S-wave velocity.
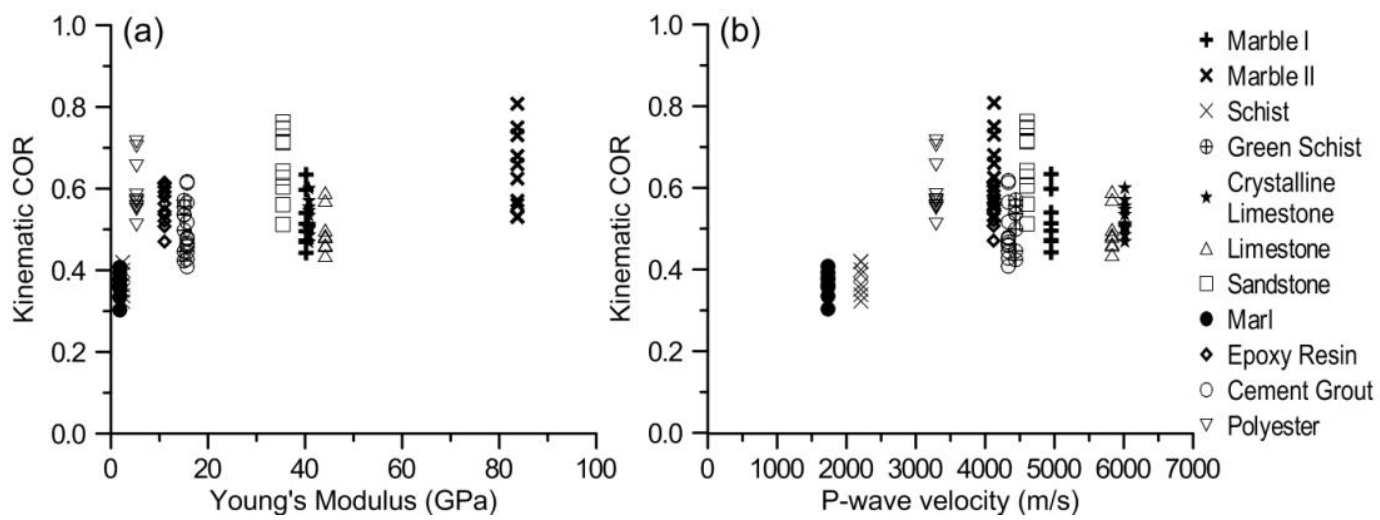

Figure 5 - Kinematic COR against tangent Young Modulus (a) and P-wave velocity (b).

\section{Schmidt Hammer Correlation}

As presented in section 4, the best correlation of kinematic COR is achieved with the Schmidt hammer rebound hardness value. This is anticipated since the operational principle of Schmidt hammer test is quite similar to the drop tests performed; Schmidt hammer measures the percentage of the energy which is recovered after an impact of a spring-loaded piston against a surface (Aydin, 2009). 
The boundary lines shown in figure $3 \mathrm{~b}$ allow a correlation of kinematic COR with rebound hardness for a chosen probability. The boundary corresponding to any chosen probability, in the range of $75 \%$ to $100 \%$, can be calculated from the following equation.

\section{Equation 7 - Probabilistic correlation of $\mathbf{v}_{\mathrm{COR}}$ with Schmidt Hammer Rebound Hardness}

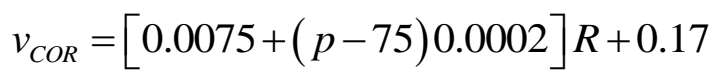

Where $\mathrm{p}(\%)$ is the probability of kinematic COR value to be less than the calculated value. This correlation is applicable for materials with Schmidt hardness greater than 15.

The additional data of $\mathrm{v}_{\mathrm{COR}}$ values from present study are plotted in the same area defined in Asteriou et al. (2012). Furthermore, the testing results of this research present significantly higher values of kinematic COR compared to those acquired by the correlation proposed by Richards et al. (2001). This could be attributed to many reasons, the most important of which is that the impact energy level used in the aforementioned study was approximately 20 times higher than the one imposed in the present experiments. It is obvious that any increase of the impact energy results in less rebound due to the larger extent of plastic deformations within the colliding entities. Additionally, Richards et al. (2001) used normal COR which results in lower values than those of kinematic COR, as previously shown. However, even though the test conditions between these studies are different, the trend and rate of change of COR values against SH rebound hardness is quite similar. An indirect method to account the effect of the imposed energy level on COR values is presented in literature (Pfeiffer et al., 1989). According to this method, COR value is scaled by an empirical factor which depends on impact velocity and represents the transition from elastic to inelastic conditions as impact velocity increases.

\section{Discussion and Conclusions}

Rockfall phenomena pose a significant hazard on human activities, which are more pronounced in the Greek territory due to the high seismicity. Accurate rockfall modeling relies amongst other parameters on the determination of restitution coefficients of the geological formations involved. The aims of the present paper were to quantify the increase of the coefficient of restitution (COR) values with increasing hardness of different rock materials and to establish correlations between their physical and mechanical properties and COR values. For this purpose a number of rock materials (marble, schist, green schist, crystalline limestone, limestone, sandstone and marl) as well as artificial materials (epoxy resin, high strength cement grout and a polyester mixture) were selected and tested in the laboratory by performing mechanical properties tests and free fall tests.

Based on the results of the present study it was concluded that kinematic COR is more concise for use in correlations compared to the normal COR. Furthermore, the kinematic COR increases with increasing hardness and shows also an increasing trend with the uniaxial compressive strength and the tensile strength. It is evident according to the experimental results, that compressive and tensile strength can be used for the prediction of kinematic COR. However, the correlation between rock hardness and kinematic COR is preferable due to the simplicity of Schmidt hammer test and the better correlation achieved.

An equation for the probabilistic determination of kinematic COR relevant to Schmidt hammer rebound hardness is proposed. The portable, quick and inexpensive measurement of Schmidt hammer renders the proposed equation as a useful tool for the acquisition of rockfall analysis parameters. 


\section{References}

Asteriou P., Saroglou H. and Tsiambaos G. 2012. Geotechnical and kinematic parameters affecting the coefficients of restitution for rock fall analysis, Int. J. Rock Mech. Min. Sci. 54, 103113.

Attewell P. and Farmer I. 1976. Principles of engineering geology. London.

Aydin A. 2009. ISRM Suggested method for determination of the Schmidt hammer rebound hardness: Revised version, Int. J. Rock Mech. Min. Sci., 46(3), 627-634.

Chau K.T., Wong R.H.C. and Wu J.J. 2002. Coefficient of restitution and rotational motions of rockfall impacts, Int. J. Rock Mech. Min. Sci., 39(1), 69-77.

Descoeudres F. and Zimmermann T. 1987. Three-dimensional dynamic calculation of rockfalls, Proc. 6th Congress Int. Soc. Rock Mech. Montreal, Vol. 1, 337-342.

Giani G.P. 1992. Rock Slope Stability Analysis, Balkema.

Goldsmith W. 1960. Impact: The theory and physical behavior of colliding solids. Edward Alrnold, London.

Heidenreich B. 2004. Small- and half-scale experimental studies of rockfall impacts on sandy slopes, PhD Thesis, Lausanne.

ISRM 2007. The complete ISRM suggested methods for Rock characterization, testing and monitoring: 1974-2006. Ulusay R, Hudson JA (eds), Ankara.

Koukis G., Tsiambaos G. and Sabatakakis N. 1994. Slope movements in the Greek territory: A statistical approach, Proc. of the 7th Int. Con. of IAEG, Lisboa, 4621-4628.

Labiouse V. and Heidenreich B. 2009. Half-scale experimental study of rockfall impacts on sandy slopes, Nat. Hazards Earth Syst. Sci., 9(6), 1981-1993.

Richards L.R., Peng B. and Bell D.H. 2001. Laboratory and field evaluation of the normal Coefficient of Restitution for rocks, Proc. of ISRM Reg. Symp. EUROCK2001, 149-155.

Paronuzzi P. 2009. Field evidence and kinematical back-analysis of block rebounds: The lavone rockfall, Northern Italy, Rock Mech. Rock Eng., 42(5), 783-813.

Pfeiffer T.J. and Bowen T.D. 1989. Computer simulation of rockfalls, Bull. of Assoc. of Eng. Geol., 26(1), 135-146.

Saroglou H., Mpekri E. and Tsiambaos G. 2010. Determination of critical geotechnical parameters of geological formations for the modeling of rockfalls in slopes, 6th Hellenic Conf. of Geotech. \& Geoenv. Eng., Volos. Vol. 2, 43-50.

Spadari M., Giacomini A., Buzzi O., Fityus S. and Giani, G. P. 2012. In situ rockfall testing in New South Wales, Australia, Int. J. Rock Mech. Min. Sci., 49, 84-93. 